
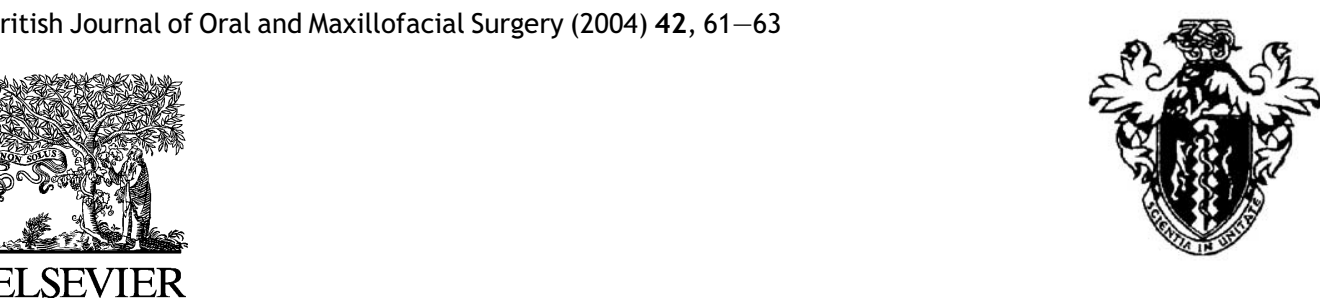

BRITISH

Journal of

Oral and

Maxillofacial

Surgery

www.bjoms.com

\title{
Closed treatment of condylar fractures by intermaxillary fixation with thermoforming plates
}

\author{
Haruhiko Terai*, Masashi Shimahara
}

Department of Oral Surgery, Osaka Medical College, 2-7 Daigaku-machi, Takatsuki-Shi, Osaka 5698686, Japan

Received 26 April 2003; accepted 5 October 2003

KEYWORDS

Intermaxillary fixation;

Condylar fracture;

Thermoforming plate

\begin{abstract}
Summary We report a new intermaxillary fixation (IMF) method for condylar fractures using a thermoforming plate. Fifteen cases of condylar fracture were selected and thermoforming plates were applied. The patient's recover was uneventful in all 15 cases, and the period of IMF ranged from 7 to 17 days, (mean 12) for the following 7 days IMF was used only at night together with functional jaw training during the day. The outcome was good. IMF using a thermoforming plate may be a useful technique for selected condylar fractures.

(c) 2003 The British Association of Oral and Maxillofacial Surgeons. Published by Elsevier Ltd. All rights reserved.
\end{abstract}

\section{Introduction}

Open reduction and internal fixation of condylar fractures may be indicated for bilateral injuries or considerably displaced condylar fractures, but closed reduction and intermaxillary fixation (IMF) may be indicated in cases where condylar displacement is minimal and the height of the ramus is almost normal.

IMF is important in the treatment of maxillofacial fractures and in orthognathic surgery, and is usually applied by wiring together the fixed upper and lower arch bars. However, wired arch bars may damage the gingival and periodontal structures because the wires tend to move apically, which results in inflammation. Recently, some types of IMF using different techniques have been reported, ${ }^{1-5}$ but these require more time, cost more, were more complicated, and required operative intervention.

\footnotetext{
${ }^{*}$ Corresponding author. Tel.: +81-72-683-1221; fax: +81-72-681-3723.

E-mail address: ora007@poh.osaka-med.ac.jp (H. Terai).
}

Lloyd et al. ${ }^{6}$ reported a new IMF technique using vacuum-formed splints with orthodontic elastics in 2001, and we reported closed treatment of jaw fractures with IMF using vacuum-formed, thermoforming plates without elastics in $2002 .^{7}$

The purpose of this study is to evaluate IMF with thermoforming plates for closed treatment of condylar fractures.

\section{Patients and methods}

Fifteen unilateral condylar fractures, (13 men and 2 women, age range 15-60 years) were selected and thermoforming plates were applied. Four fractures were slightly displaced, five were displaced, and six were dislocated. All patients were treated by closed reduction between September 1999 and March 2002 (Table 1). The technique has been described elsewhere. ${ }^{7}$ During the period of IMF, the thermoforming plate was removed while the patient took a liquid diet three times a day. The period of IMF ranged from 7 to 17 days (mean 12). 
Table 1 Details of patients treated.

\begin{tabular}{lllll}
\hline Case number & Age (year)/sex & Fracture & \multicolumn{2}{c}{ Intermaxillary fixation (days) } \\
\cline { 3 - 4 } & & & All day IMF & Night alone \\
\hline 1 & $53 \mathrm{~F}$ & Dislocated & 10 & 7 \\
2 & $20 \mathrm{M}$ & Slightly displaced & 7 & 7 \\
3 & $24 \mathrm{M}$ & Dislocated & 13 & 7 \\
4 & $19 \mathrm{M}$ & Displaced & 17 & 7 \\
5 & $60 \mathrm{M}$ & Displaced & 13 & 7 \\
6 & $50 \mathrm{M}$ & Displaced & 10 & 10 \\
7 & $54 \mathrm{M}$ & Dislocated & 14 & 7 \\
8 & $24 \mathrm{M}$ & Slightly displaced & 11 & 7 \\
9 & $15 \mathrm{M}$ & Displaced & 10 & 7 \\
10 & $34 \mathrm{M}$ & Slightly displaced & 8 & 7 \\
11 & $24 \mathrm{M}$ & Dislocated & 15 & 7 \\
12 & $35 \mathrm{~F}$ & Dislocated & 12 & 7 \\
13 & $19 \mathrm{M}$ & Slightly displaced & 10 & 7 \\
14 & $29 \mathrm{M}$ & Displaced & 14 & 7.4 \\
15 & $38 \mathrm{M}$ & Dislocated & 14 & 7 \\
Mean & & & 11.9 & \\
\hline
\end{tabular}

During the next 7 days, IMF all day was followed by IMF only at night together with functional jaw training during the day (Table 1).

\section{Results}

All patients recovered uneventfully, and dentition, occlusion, and periodontal tissue were within normal clinical ranges (Fig. 1). The fixation strength of the plate was appropriate in all cases. Of the $15 \mathrm{pa}$ tients we could evaluate the outcome in 11 patients 4-6 months after treatment, and all 11 patients could open their mouths over $40 \mathrm{~mm}$ (or three fingers breadth). Three patients complained of an uncomfortable feeling or mild pain of the condyle on the fractured side during maximum opening, and 5

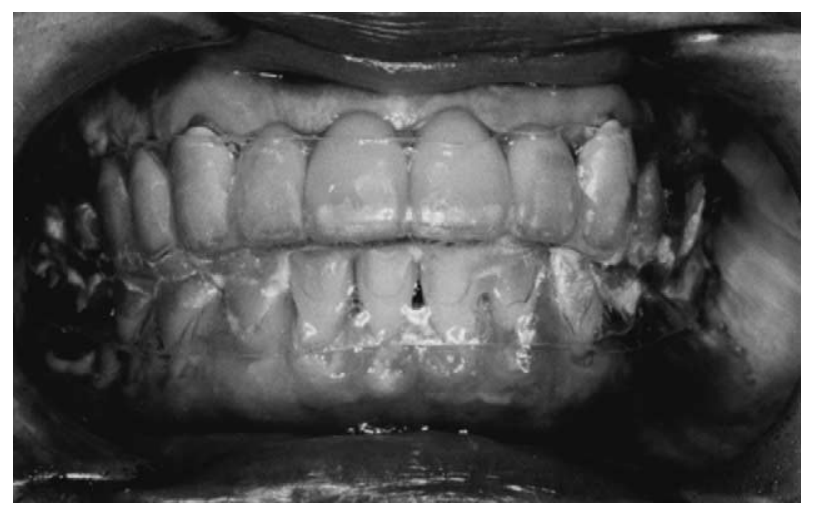

Figure 1 Intermaxillary fixation with the thermoforming plates in place. patients opened their mouths with slight deviation to the fractured side within $5 \mathrm{~mm}$. There were no limitations of jaw function in any case.

\section{Discussion}

Many methods of IMF have been reported. ${ }^{1-6}$ The vacuum-formed splint $^{6}$ and our thermoforming plates are almost the same materials and system, which has been widely used for periodontal splints, night guards, bite splints, and so on. They are characterized by clarity, their smooth surface, and ease of cutting. The clarity permits easy checking of adaptation and occlusion. The smooth surface makes their comfortable to wear without risk of puncturing the operator's skin, or injuring the patient's periodontal tissue. The ease of cutting makes trimming easy and shortens the treatment. A vacuum-formed splint and the thermoforming plate have many advantages for IMF, but the main difference between them is that the plate is made from a two-layered sheet: the inner soft layer and the outer hard layer. The inner soft layer makes retention adequate for IMF without the use of elastics, so the fixation strength was appropriate in all cases. The outer hard layer gives it appropriate flexibility, and it can also be released easily in the event of acute airway obstruction.

Our outcome of 11 patients at 4-6 months after the treatment suggested that IMF with a thermoforming plate was useful for closed treatment of unilateral condylar fractures. However, it has 
some limitations for condylar fractures that require closed reduction. The fixation strength is less than that of wiring, so it is contraindicated for bilateral condylar fractures with open bite. In addition, it must be taken off when eating, so if there is free movement between segments of an associated fracture of the mandibular body it is also contraindicated. IMF using with a thermoforming plate may be applied after open reduction in these cases.

\section{References}

1. Schuchardt K. Ein Vorschlag zue Verbesserung der Drahtschienenverbände [A proposal to improvement of wire splint ligature]. Dtsch Zahn Mund Kieferheilkd 1956;24:3944.

2. Honig JF. The Göttingen quick arch-bar. A new technique of arch-bar fixation without ligature wires. J Craniomaxillofac Surg 1991;19:366-8.

3. Baurmash HB. Bonded arch bars in oral and maxillofacial surgery: an update. Oral Surg Oral Med Oral Pathol 1993;76:553-6.

4. Rosenberg FA, Distefano JF, Byers SS. Adhesive bonding of arch bars for maxillomandibular fixation. J Oral Surg 1976;34:651-3.

5. Divis BO. New device for interdental immobilization. Ann Oral Rhinol laryngol 1992;101:776-8.

6. Lloyd T, Nightingale C, Edler R. The use of vacuum-formed splints for temporary intermaxillary fixation in the management of unilateral condylar fractures. Br J Oral Maxillofac Surg 2001;39:301-3.

7. Terai $\mathrm{H}$, Shimahara $\mathrm{M}$. Intermaxillary fixation using thermoforming plate. J Oral Maxillofac Surg 2002;60:1092-4.

Available online at www.sciencedirect.com

science $\mathcal{d}$ Directo 